\section{LONGHORNED BEETLES (COLEOPTERA: CERAMBYCIDAE) FROM CHHATTISGARH, INDIA}

\section{Amitava Majumder ${ }^{1}$, Angshuman Raha ${ }^{2}$, Bulganin Mitra $^{3}$, H.V. Ghate ${ }^{4}$ \& Kailash Chandra ${ }^{5}$}

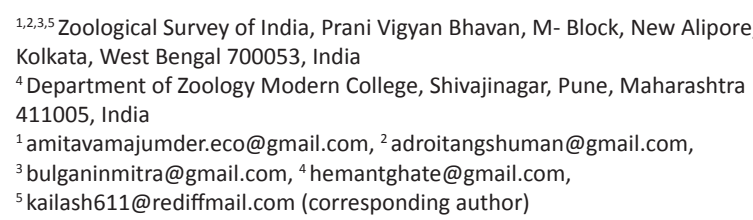

${ }^{4}$ Department of Zoology Modern College, Shivajinagar, Pune, Maharashtra 411005, India

${ }^{1}$ amitavamajumder.eco@gmail.com, ${ }^{2}$ adroitangshuman@gmail.com,

${ }^{3}$ bulganinmitra@gmail.com, ${ }^{4}$ hemantghate@gmail.com,

${ }^{5}$ kailash611@rediffmail.com (corresponding author)

The pioneering taxonomic and biological investigations on cerambycid beetles in India were initiated in the 20th century. Gahan (1906) was the first to compile and describe the known cerambycid beetles, excluding Lamiinae, from the Indian region in the 'Fauna of British India'. After that, extensive work on the diversity and distribution of cerambycids from India is particularly lacking.

Some scattered publications on longhorned beetles of India by White (1853), Sengupta \& Sengupta (1981), Khan \& Maiti (1983), Basak \& Biswas (1985, 1993), Biswas \& Basak (1992), Raychaudhuri \& Saha (2000), Mukhopadhyay \& Biswas $(2000,2002)$ and Mukhopadhyay \& Halder $(2003,2004)$ are available. Recently, Sen \& Ghate (2006) and Ghate (2012) also published some information on cerambycid fauna of Maharashtra, India.

This report is the first report on the family cerambycidae from the state of Chhattisgarh after its separation from the erstwhile Madhya Pradesh State. The present study accounts for 10 species of Cerambycid beetles belonging to eight genera and six tribes under two subfamilies and constitute a first record from
Chhattisgarh State.

Materials and Methods: Study period: The specimens were collected from different parts of Chhattisgarh during the period July 2011 to December 2012. Collections were mostly made during the monsoon (July to September) and post monsoon (October and November) seasons.

Study area: Chhattisgarh is a newly carved out state from Madhya Pradesh in 2001. The state extends between $17^{\circ} 46^{\prime}-24^{\circ} 8^{\prime} \mathrm{N}$ and $80^{\circ} 15^{\prime}-84^{\circ} 24^{\prime} \mathrm{E}$ in the central Indian landscape having a total area of $1,35,194 \mathrm{~km}^{2}$. Nearly $44 \%$ of the area is covered by forests but a major part $\left(35,736.239 \mathrm{~km}^{2}\right)$ is outside protected areas. Biogeographically, the state belongs to the Deccan Plateau and includes provinces, 6D-Chota Nagpur Plateau, 6C-Eastern Highland and 6E-Central Highland (Rodgers et al. 2002).

Methods: Cerambycid beetles are best collected at night with the help of a light trap. Mercury bulbs (160 Watt) were used to attract insects on a white sheet of cloth measuring approximately $2 \times 2 \mathrm{~m}$. The coordinates of the collection sites were recorded using GPS (Garmin Oregon 550) which were further used in preparing maps of the survey sites in DIVA-GIS (Fig. 1). Specimens were studied under Leica EZ4 HD binocular microscope for identification. The specimens were identified with the help of available published literature on Cerambycidae from India and confirmed by comparing the reference collection of National Zoological Collection at Zoological Survey of India, Kolkata. The studied material is deposited in the National Zoological Collection, Zoological Survey of India, Kolkata.

DOI: http://dx.doi.org/10.11609/JoTT.o3601.5393-9 | ZooBank: urn:Isid:zoobank.org:pub:19B8D44E-FEB8-414F-A5EC-958F0FF9B74E

Citation: Majumder, A., A. Raha, B. Mitra, H.V. Ghate \& K. Chandra (2014). Longhorned beetles (Coleoptera: Cerambycidae) from Chhattisgarh, India. Journal of Threatened Taxa 6(1): 5393-5399; http://dx.doi.org/10.11609/JoTT.03601.5393-9

Copyright: (c) Majumder et al. 2014. Creative Commons Attribution 3.0 Unported License. JoTT allows unrestricted use of this article in any medium, reproduction and distribution by providing adequate credit to the authors and the source of publication.

Funding: Chhattisgarh CAMPA (Compensatory Afforestation Management and Planning Authority).

Competing Interest: The authors declare no competing interests.

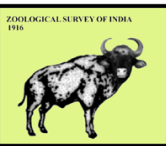

Acknowledgements: Authors are grateful to Dr. K. Venkataraman, Director, Zoological Survey of India, for providing necessary facilities and encouragements. Thanks are also due to Chhattisgarh Forest Department for providing necessary permissions and support to carry out the present work 


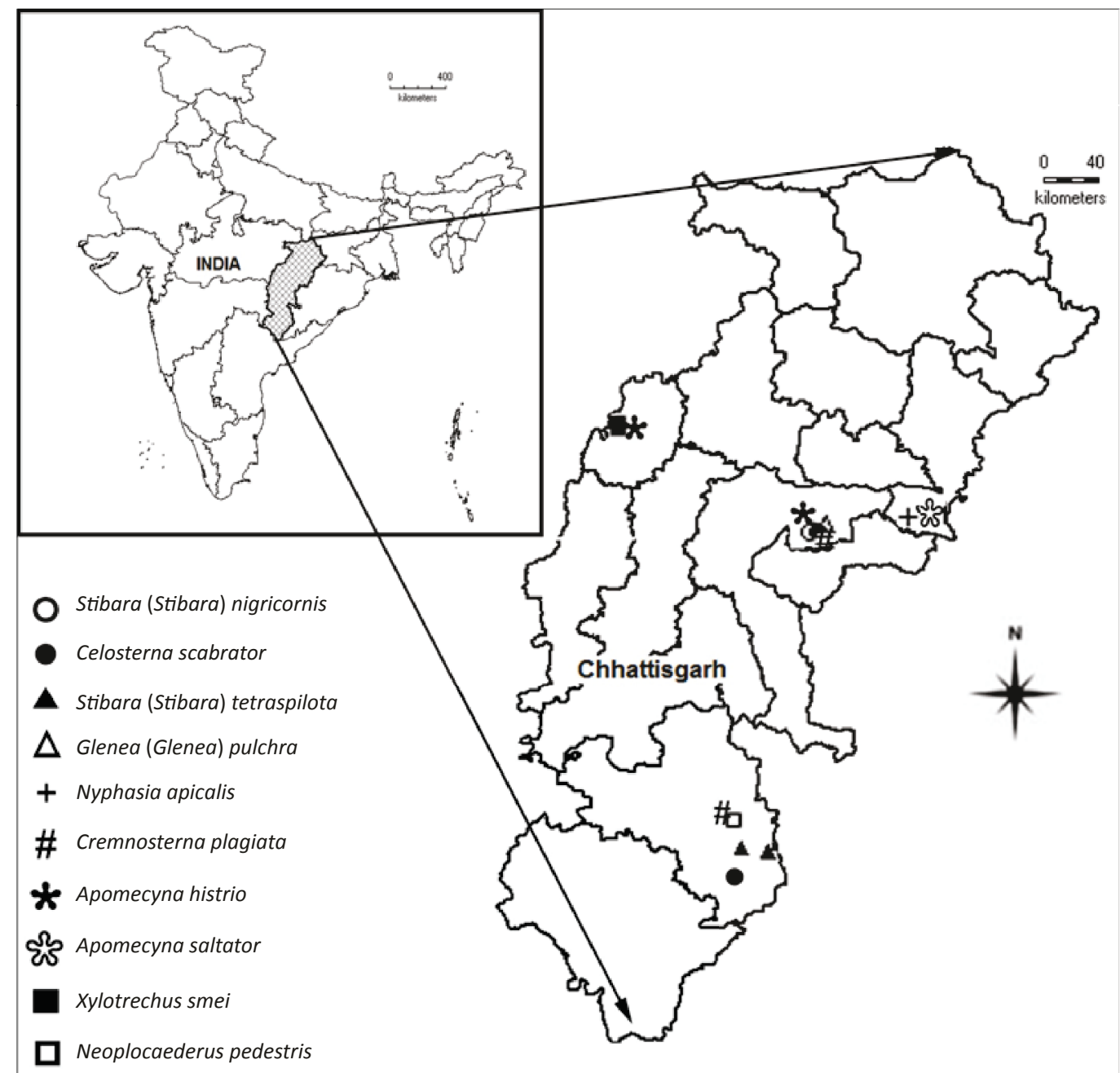

Figure 1. Survey sites in Chhattisgarh

Results:

Subfamily: Cerambycinae

Tribe: Phoracanthini

Nyphasia apicalis Gahan (Image 1)

1893. Nyphasia apicalis Gahan, The Annals and Magazine of Natural History (6)11: 378

1987. Nyphasia apicalis Khan \& Khan, Proceedings of the Indian Academy of Science (Animal Sciences) 96(4): 403-415.

Material examined: 19754/H4A, 2.xi.2012 (1 ex.), Raigarh, Gomerdha Wildlife Sanctuary (WS),

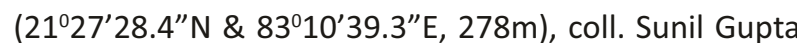
and Party.

Diagnosis: Small sized, body bright reddish-brown in colour, head darker than body, pronotum, legs and scape, elongated; head transverse, eyes large, black, upper lobe much smaller than lower one, antennae 11 segmented longer than body, segment 1 and 2 dark brown and rest black, segment 1 small dumb-bell shaped, segment-3 longer than segment-1, rest of the segments gradually longer, segment 3 to 6 apically broad with acute spine on the inner margin, rest devoid of spines; pronotum globular, with obtuse tubercles on disc, longer than broad, dark brown with black faint patches, lateral margins irregular, densely punctate; elytra dark brown, elongated, slender, apex charcoal black coloured, a few fine longitudinal ridges throughout elytra; legs dark brown, basal region of the femur slender, abruptly bulged at the apex, tarsal claw divergent.

Distribution: India (Gahan 1906): Chhattisgarh (Raipur), Maharashtra (Ghate 2012), West Bengal (Khan \& Khan 1987).

Tribe: Cerambycini

Neoplocaederus pedestris (White) (Image 2)

1853. Hammaticherus pedestris White, Cat. Col. B.M., Longic: 127.

1906. Plocaederus humeralis Gahan, Fauna of 
British India, including Ceylon \& Burma, Coleoptera: Cerambycidae: 123.

1991. Neoplocaederus pedestris Sama, Bollettino della Società Entomologica Italiana 123(2): 121-128.

Material examined: 19747/H4A, 20.x.2011 (1 ex.), Bastar, Jagdalpur, Nandpura beat $\left(19^{\circ} 21^{\prime} 37.7^{\prime \prime} \mathrm{N}\right.$ \& 81054'12.9"E, 583m), coll. R.P. Gupta and Party.

Diagnosis: Body large, elongate, deep black throughout; head protuberant, horizontal, eyes very large, finely faceted, black in colour, weakly subdivided, both the eyes separated by a narrow carina, antennae 11-segmented, ferruginous, segment-1 small, thick, as long as segment-3, segment-5 to 10 dorso-apically raised; pronotum broader than long, surface rough with ridges and punctures, sparsely pubescent, these gradually get dense towards lateral margins, small distinct tubercle on either side of the mid lateral margins of the pronotum; elytra elongated, parallel sided, black with dense greyish pubescence, humeral angles raised, few indistinct longitudinal ridges on the elytra, basal margin widened, compressed at the middle, gradually widened towards apex, apex narrowly truncated, sutural spine acute, lateral spine blunt; legs ferruginous, with femoral tips black, pubescent, femur thick, elongated, tibia slender, tarsal claws divergent.

Distribution: India (Gahan 1906): Chhattisgarh (Bastar); Mayanmar (http://www.cerambycoidea.com)

Tribe: Clytini

Xylotrechus smei (Laporte \& Gory) (Image 3)

1841. Clytus vicinus Laporte \& Gory, Hist. Nat. et. Lconogrdes Ins. Coleopt (Mon du genre Clytus): 37.

1841. Clytus smei Laporte \& Gory, Hist. Nat. et. Lconogrdes Ins. Coleopt (Mon du genre Clytus): 37.

1906. Xylotrechus smei Gahan, Fauna of British India, including Ceylon \& Burma, Coleoptera: Cerambycidae: 241-242.

Material examined: 19748/H4A, 01.ix.2011 (1 ex.),Kabirdham, Bhoramdev WS, Chilpi rest house (22 $\left.{ }^{\circ} 11^{\prime} 1.1^{\prime \prime} \mathrm{N} \& 81^{\circ} 2^{\prime} 58.3^{\prime \prime} \mathrm{E}\right)$, coll. Sunil and Party.

Diagnosis: Small sized, dark brown, ornamented with whitish and blackish patches and bands throughout, head horizontal, eyes a little incised, finely faceted, centrally black, surrounded by coppery facets; antennae very small, hardly surpassing the fore leg, segment-1 thickened, segment-3 longest; pronotum globular, dark brown in colour, densely, finely punctate with spars whitish pubescence, two semicircular black patches of pubescence prominently marked on either side of the pronotum at the middle; elytra dark brown, pubescent throughout, basal region with off white pubescence, running downwards along the sutural margin, another two longitudinal bands from behind the scutellum and running towards apex, gradually out curved towards lateral margin at the middle of elytra, two wavy pale whitish bands on either side of elytra just behind the hind leg, two more irregular shaped whitish patches of pubescence on the lateral margin of the basal region, apex substrate, elytra with whitish patches of pubescence, lateral angle with small spine; femora thickened, claws widely divergent.

Distribution: India: Sikkim (Mukhopadhyay \& Halder 2003), Maharashtra (Ghate 2012), Orissa (Basak \& Biswas 1993) and Chhattisgarh (Kabirdham); Pakistan; Nepal; Bhutan; Mayanmar; Introduced in Thailand (1985); Tunisia; France; Switzerland; Germany (2000); Italy (1982); Greece (1990); Israel (1998); Tanzania (1968); Intercepted in USA (1996) (http://www.cerambycoidea.com).

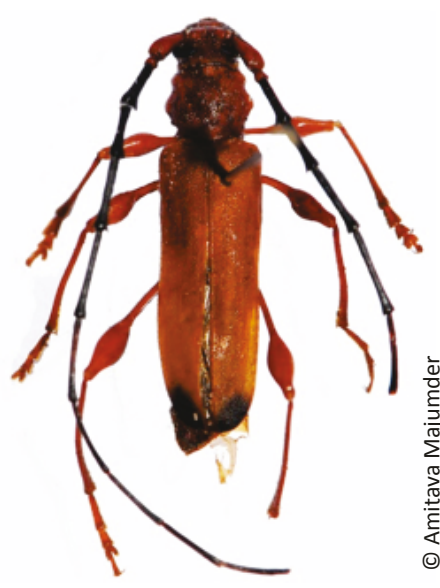

Image 1. Nyphasia apicalis Gahan

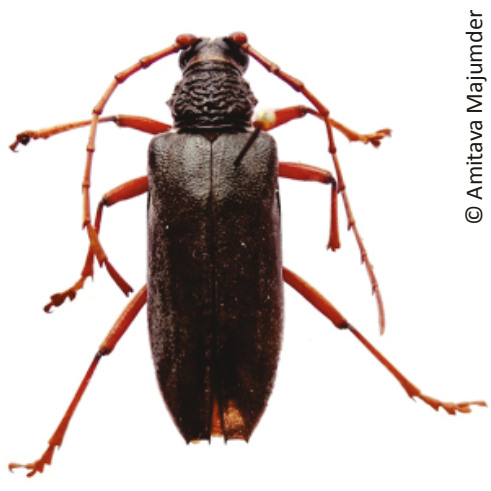

Image 2. Neoplocaederus pedestris (White)

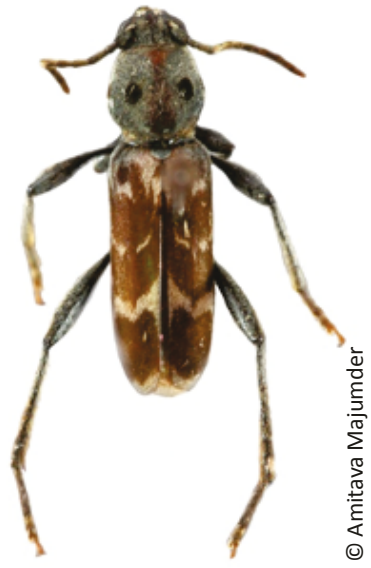

Image 3. Xylotrechus smei (Laporte \& Gory) 
Subfamily: Lamiinae

Tribe: Agniini

Celosterna scabrator (Fabricius) (Image 4)

1781. Lamia scabrator Fabricius, Sepcies insectorvm., Hambvri et Kilonii, 1(1-8): 224

1970. Celosterna scabrator Gressitt, Rondon \& Breuning, Pacific Insects Monograph, Bishop Museum, Honolulu. 24: 1-314.

Material examined: 19733/H4A-19744/H4A, Raipur, Barnawapara WS, Barnawapara rest house, 4.vii.2011 (1 ex.), 3.vii.2011, (1 ex.), 26.vii.2011, (1 ex.), 27.vii.2011, (1 ex.), 4.ix.2011, (1 ex.), 6.ix.2011, (1 ex.), 24.ix.2011, (1 ex.), 7.x.2011, (1 ex.); Gabod, 20.vii.2011, (1 ex.); Charoinda, 19.vii.2011, (1 ex.); Dengaon, 5.viii.2011, (1 ex.); Bhimbori, 26.vii.2011, (1 ex.), coll. Sunil and Party; 19745/H4A and 19746/H4A, Bastar, Jagdalpur, Tirathgarh, (18054'47.1"N \& 81051'57.8” $\mathrm{E}, 604 \mathrm{~m})$, 26.vii.2012, (1 ex.); Bhanpuri FRH, $\left(19^{0} 19^{\prime} 35.1^{\prime \prime} \mathrm{N}\right.$ \& 81050'8.8”E), 16.x.2011, (1 ex.), coll. R. P. Gupta and Party.

Diagnosis: Medium-sized, elongate, slender, ashygrey, covered with pale yellowish dense pubescence, pronotum more darker, head and legs wholly ashy-grey; head vertical, eyes black, both the lobes separated widely, subdivided, upper lobe smaller than lower lobe; antenna 11-segmented, as long as body, clothed with pubescence, segments ashy-grey throughout with dark brown apical area, segment-1 robust, segment -3 a little longer than segment-1, rest equal in size; pronotum rectangular, ashy-grey with dense pale yellow pubescence, sparsely punctate, medially deeply incised, surface gibbous and strongly punctate; lateral margins with acute, prominent spines; scutellum small, tongue shaped, brownish in colour; elytra elongated, basally broad, narrowed towards apex, apex truncated, shoulder hump prominent, basal region with large black granules, densely, coarsely, punctate these gradually get finer towards apex, punctuation dark brown in colour on the basal region; legs densely pubescent, mid and hind tibia apically spined, tarsal claw almost $90^{\circ}$ angle; venter densely pubescent.

Distribution: India: Tamil Nadu (Namboodiri \& Thirumalai 2009), Maharashtra (Ghate 2012), Orissa (Basak \& Biswas 1993) and Chhattisgarh (Bastar and Raipur); Pakistan; Ceylon; Nepal; Vietnam; Laos; Introduced in Madagascar and Réunion. (http://www. cerambycoidea.com)

\section{Cremnosterna plagiata (White) (Image 5)}

1858. Cerosterna plagiata White, Proceedings of the Zoological Society of London 26: 403

1970. Cremnosterna plagiata Gressitt, Rondon \& Breuning, Pacific Insects Monograph Bishop Museum, Honolulu. 24: 429.

Material examined: 19752/H4A, Bastar, Jagdalpur, Nandpura Beat, (19021'37.7"N \& 81054'12.9”E, 583m), 20.x.2011, (1 ex.), coll. R.P. Gupta and Party; 19753/H4A, Raipur, Barnawapara WS, Latadadar, 8.vii.2011, (1 ex.), coll. Sunil and Party.

Diagnosis: Medium-sized, slender, brownish-yellow, densely pubescent throughout, ornamented with some black and white patches, more on elytra; head vertical, frons wide, sub quadrate, densely pubescent, eyes large, subdivided, presence of two large black prominent patches on either side of the vertex below the upper lobe of eyes; antennae 11 segmented, densely pubescent, hairs on the inner margin, segments 3 to 11

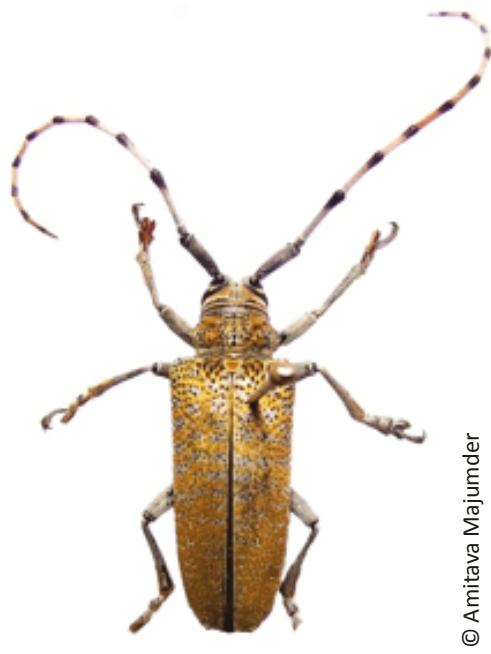

Image 4. Celosterna scabrator (Fabricius)

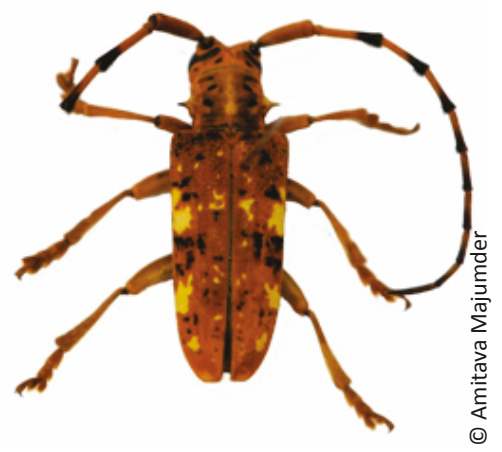

Image 5. Cremnosterna plagiata White

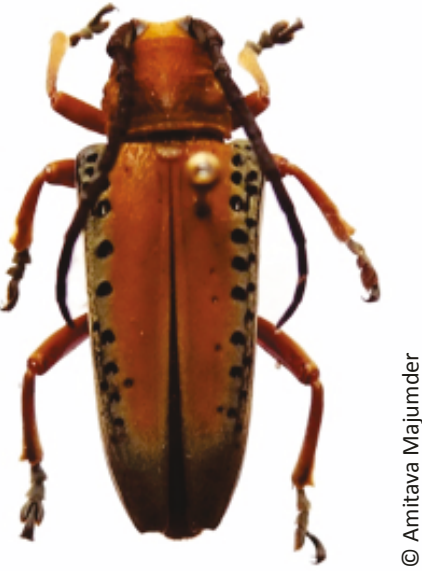

Image 6. Stibara (Stibara) nigricornis (Fabricius) 
apically dark brown with tuft of hairs, segment 1 as long as segment-3; pronotum cylindrical, longer than broad, densely pubescent, surface somewhat rough, two black patches of pubescence present medially on the either side of the pronotum, spines large, prominent, at the latero-median region of pronotum; elytra elongate, basally widened, gradually narrowed towards apex, clothed with brownish-yellow pubescence throughout, ornamented with various shapes and sizes of black patches throughout, three large white prominent patches of pubescence on either side of the elytra close to lateral margin, some more small, white spots present throughout elytra, apex of elytra substrate; legs brownish-yellow, tarsal claws divergent.

Distribution: India (Gahan 1906): Maharashtra and Chhattisgarh (Bastar, Raipur); Malayan Peninsula; Myanmar; Pakistan; Thailand (http://www.lamiinae. org).

\section{Tribe: Saperdini}

\section{Stibara (Stibara) nigricornis (Fabricius) (Image 6)}

1781. Lamia nigricornis Fabricius, Spec. Ins. : 218

1890. Stibara nigricornis Gahan, Ann. Mag. Nat. Hist., (6) V, p. 66

1954. Stibara (Stibara) nigricornis, Ent. Arb. Mus. Frey, Bd. $5: 468$

2006. Stibara (Stibara) nigricornis Sen \& Ghate, Zoos' Print Journal 21(3): 2198

Material examined: 19704/H4A \& 19705/H4A 02.vii.2011, (2 exs.), Raipur, Barnawapara WS, Dond nala, coll. K. Chandra; 19698/H4A-19703/H4A, 10.vii.2011 (6 exs.), coll. Sunil and Party.

Diagnosis: Body medium-sized, elongate, yellowishorange in colour, pronotum more darker, sparsely pubescent, more in lateral sides; head vertical, eyes large, black, strongly sub divided, antennae black, 11-segmented and hardly surpassing mid legs, segment1 thick, as long as segment-3; pronotum longer than broad, surface smooth, sparsely punctate, lateral margins a little out curved at the middle, elytra yellowish orange, lateral margin with longitudinal carina, more strongly on basal region, gradually weaker towards apex, more wider towards apex, a longitudinal wide ashy patch of pubescence present throughout the carinated area, more wider near apex, a row of black, large, deep punctures present on the dorso-lateral margin of elytra along the carina, another row of punctures starting from the meso-sternum region on the lateral margin of the elytra, apex of the elytra somewhat substrate; femur robust, tibia thickened at the apex, rainure near the apex, tarsal claws divergent.
Distribution: India: Maharashtra (Ghate 2012) and Chhattisgarh (Raipur).

\section{Stibara (Stibara) tetraspilota Hope (Image 7)}

1840. Stibara tetraspilota Hope, Proceedings of the Linnean Society of London 1: 79.

1954. Stibara (Stibara) tetraspilota, Breuning,: Ent. Arb. Mus. Frey, Bd. 5,: 465

2006. Stibara (Stibara) tetraspilota Sen \& Ghate. Zoos' Print Journal 21(3): 2198

Material examined: 19706/H4A-19714/H4A, 19719/ H4A-19722/H4A, 23.vi.2012 (13 exs.), Bastar, Jagdalpur, Tekameta $\left(19^{\circ} 05^{\prime} 19.3^{\prime \prime} \mathrm{N}\right.$ \& 81056'13.9" $\left.\mathrm{E}, 562 \mathrm{~m}\right)$; 19723/H4A-19731/H4A, 25.vii.2012 (9 exs.), Dharmour, $\left(19^{\circ} 06^{\prime} 1.9^{\prime \prime} \mathrm{N} \& 81^{\circ} 59^{\prime} 2.7^{\prime \prime} \mathrm{E}, 550 \mathrm{~m}\right)$, coll. R. P. Gupta and Party.

Diagnosis: Body medium-sized, elongated, yellowish -brown, sparsely pubescent, legs brownish; antennae 11-segmented, rusty black, smaller than body, inner margin with sparse hairs, segment 1 thick, pubescent, smaller than segment 3; head vertical, eyes finely faceted, pitchy black; vertex wider in between the eyes, median line distinct; pronotum deep reddish-yellow, smooth, a little wider at the middle, scutellum broadly $U$ shaped; elytra yellowish-brown, except basal and apical, sparsely punctate, 1 longitudinal strong carina originated from the humeral angle, gradually weaken towards apex, basal region on either side of the lateral margin with rusty black colour and densely punctate, $1 / 3^{\text {rd }}$ of the apical region with same colour as basal margin, apex substrate; legs yellowish-brown, tarsal claw more than $90^{\circ}$ angle.

Distribution: India: Meghalaya (Mukhopadhyay \& Biswas 2000), Sikkim (Mukhopadhyay \& Halder 2003), Orissa (Basak \& Biswas 1993), Tripura (Agarwala \& Bhattacharjee 2012) and Chhattisgarh (Bastar); Myanmar; Thailand; Vietnam (http://www.cerambycoidea.com)

\section{Glenea (Glenea) pulchra Aurivillius (Image 8)}

1926. Glenea (Glenea) pulchra Aurivillius, Philip. J. Sci. 30: 111

1970. Glenea (Glenea) pulchra Gressitt, Rondon \& Breuning, S. Pacific Insects Monograph, Bishop Museum, Honolulu. 24: 531

Material examined: 19732/H4A, 13.vii.2011 (1 ex.), Raipur, Barnawapara WS, Nawapara $\left(21^{0} 25.728^{\prime} \mathrm{N}\right.$ \& $\left.82^{\circ} 27.467^{\prime} \mathrm{E}, 308 \mathrm{~m}\right)$, coll. Sunil and Party.

Diagnosis: Body medium-sized, slender, dark brown throughout, covered with sparse yellowish pubescence with bluish-green lustre ; punctation throughout, more in elytra, head vertical, margin of the eyes lined with 


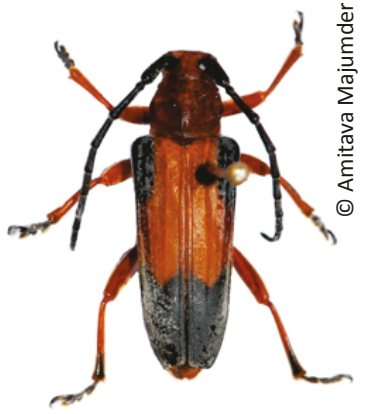

Image 7. Stibara (Stibara) tetraspilota Hope

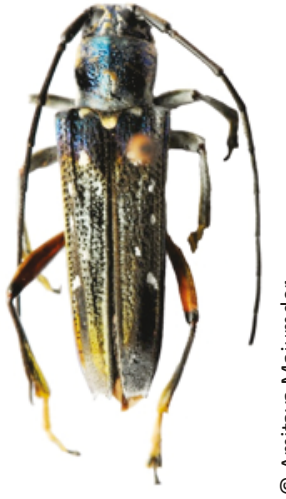

Image 8. Glenea (Glenea) pulchra Aurivillius

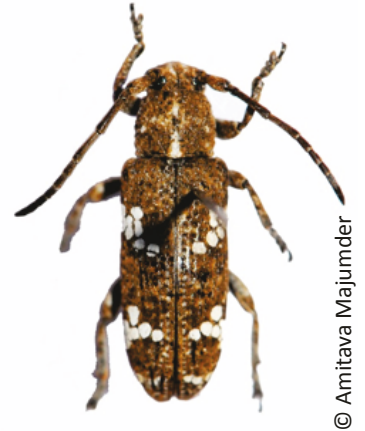

Image 9. Apomecyna saltator (Fabricius)

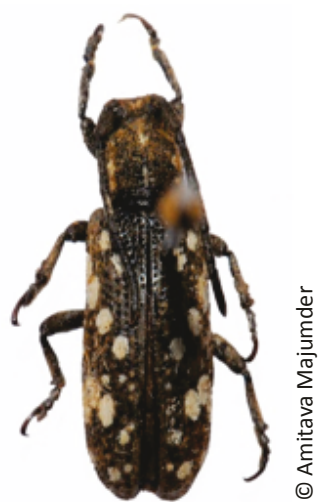

Image 10. Apomecyna histrio (Fabricius) yellowish pubescence; eyes sub divided; antennae 11-segmented, black, inner margin of segment 1-4 hairy, segment-1 small and the segment-3 longest; pronotum with metallic blue lustre, cylindrical, longer than broad, densely punctate, larger towards middle; lateral margin clothed with white pubescence; scutellum broadly ' $U$ ' shaped densely pubescent, elytra elongated, convergent towards apex, densely and strongly punctate at the basal region gradually finer towards apex, dark brown, ornamented with some pale white patches, two at the basal margin near scutellum, two large patches behind the middle legs near sutural margin, three at the lateral margin of elytra in between middle legs and apex of elytra, two small patches behind the hind leg near sutural margin, apex of the elytra truncated with long hairs, sutural and lateral margins with small spines, legs sparsely pubescent, femur elongated and robust, tibia slender, tarsal claws more than $90^{\circ}$ angle.

Distribution: India: Assam, Sikkim (Gressitt et al. 1970) and Chhattisgarh (Raipur); China (Kwangsi, Taiwan); Myanmar; Thailand; Laos; Vietnam; Malaysia (http://www.cerambycoidea.com)

\section{Tribe Apomecynini}

\section{Apomecyna saltator (Fabricius) (Image 9)}

1781. Lamia saltator Fabricius, Mant. Ins. 1: 141.

1992. Apomecyna saltator Biswas \& Basak, Records of the Zoological Survey of India 92(1-4): 169.

Material examined: 19749/H4A, 18.xi.2012 (1 ex.),

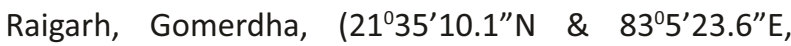
$253 \mathrm{~m})$, Coll. Sunil and Party.

Diagnosis: Small-sized, dark brown, elongated, ornamented with white spots, head sub rounded, covered with dense yellowish-brown pubescence; eyes divided in two parts, upper lobe smaller than the lower lobe, finely faceted black in colour; antennae black, hardly surpassing the hind legs, covered with yellowish pubescence, segment-3 much longer than segment1 , a little longer than 4, rest equal in size; pronotum cylindrical, covered with brown pubescence and punctate; surface ornamented with white longitudinal post median band, two faint patches of the same color present on the lateral side of the pronotum, elytra elongated, apex sub rounded, covered with yellowish brown pubescence, six irregular shaped white patches on the lateral margin in between middle and hind legs present, nine irregular patches on the lateral margin, behind the hind leg, third row of patches consists of three transversely placed between lateral and sutural margin near apex.

Distribution: India: Tamil Nadu (Namboodiri \& Thirumalai 2009), Orissa (Basak \& Biswas 1993), Arunachal Pradesh (Sengupta \& Sengupta 1981), Chhattisgarh (Raigarh); Singapore; Taiwan island (Biswas \& Basak); Pakistan; Subtropical China; Vietnam; Taiwan ( http://www.lamiinae.org).

\section{Apomecyna histrio (Fabricius) (Image 10)}

1792. Lamia histrio Fabricius, Entomologia systematica emendata et aucta.: 288.

1992. Apomecyna histrio Biswas \& Basak, Records of the Zoological Survey of India. 92(1-4): 164.

Material examined: 19750/H4A, 8.vii.2011, (1 ex.), Raipur, Barnawapara WS, Latadadar; 19751/H4A, 29.viii.2011, (1 ex.), Kabirdham, Bhoramdev WS, Chilpi Rest house $\left(22^{\circ} 10^{\prime} 22.6^{\prime \prime} \mathrm{N} \& 81^{0} 3^{\prime} 3.6^{\prime \prime} \mathrm{E}, 791 \mathrm{~m}\right)$, coll. Sunil and Party.

Diagnosis: Small-sized, dark brown, elongated, decorated with white spots, head almost rounded in shape, covered with dense yellowish-brown pubescence; Eyes divided in two parts, upper lobe smaller than the lower lobe, eyes finely faceted, black in colour; gena sub 
quadrate, frons sub quadrate; antennae black, hardly extending up to the middle of the elytra, covered with yellowish pubescence, $3^{\text {rd }}$ and $4^{\text {th }}$ segment larger, $5^{\text {th }}$ to $11^{\text {th }}$ segments small, equal in size, pronotum cylindrical, covered with brown pubescence and punctures; pronotum decorated with white patches, two laterals on mid dorsal line and other two longitudinally at the apex of pronotum, elytra elongated, apex not fully rounded, covered with yellowish-brown pubescence; elytra decorated with longitudinal transverse white rounded patch, patches are variable in number, arranged in four transverse bands, first and last band are small, usually composed of two patches; elytra covered with dense longitudinal punctures; scutellum tongue shaped, covered with yellowish-brown pubescence.

Distribution: India: Tamil Nadu (Namboodiri \& Thirumalai 2009) and Chhattisgarh (Raipur, Kabirdham) ; Russia; Korea; Japan; China; Laos; Thailand; Philippines; Indonesia (Borneo, Sumatra, Sunda Islands, Moluccas); New Guinea; Australia (Queensland). (http://www. cerambycoidea.com).

Discussion: The present report is the first comprehensive account on the cerambycid beetles from Chhattisgarh. The state's forest cover is almost $60 \%$ which indicates very good timber production. It is imperative to study the longhorned beetles being destructive to forests. A thorough survey in different areas of the state can reveal more than twice the number of species reported in this paper.

\section{References}

Agarwala, B.K. \& P.P. Bhattacharjee (2012). Long-horned Beetles (Coleoptera: Cerambycidae) and Tortoise Beetles (Chrysomelidae: Cassidinae) of Tripura, northeastern India with some new additions. Journal of Threatened Taxa 4(13): 3223-3227; http://dx.doi. org/10.11609/JoTT.o2951.3223-7

Basak, P.K. \& S. Biswas (1985). Fauna of Namdhapa (Insecta: Coleoptera: Cerambycidae) National Park. Records of the Zoological Survey of India 82(1-4): 215-219.

Basak, P.K. \& S. Biswas (1993). Fauna of Orissa. State Fauna Series. Zoological Survey of India, Kolkata 1(4): 185-195.
Biswas, S. \& P.K. Basak (1992). Studies on Longicorn beetles (Coleoptera: Cerambycidae) from India Part I. On Indian species Apomecyna Latreille with a key to Indian genera of tribe Apomecynini. Records of the Zoological Survey of India 92(1-4): 161-172.

Gahan, C.J. (1906). The Fauna of British India including Ceylon and Burma. Coleoptera: Cerambycidae. Taylor and Francis, London, 329pp.

Ghate, H.V. (2012). Insecta: Coleoptera: Cerambycidae. In: Director (ed.). Fauna of Maharashtra, State Fauna Series 20 (Part 2). Zoological Survey of India, Kolkata, India: 503-505.

Gressitt, J.L., J.A. Rondon \& S. Breuning (1970). Cerambycid beetles of Laos. Pacific Insect Monograph 24: 1-651.

Khan, T.N. \& P.K. Maiti (1983). Studies on the biotaxonomy, biology and ecology of some longicorn beetle borers (Coleoptera: Cerambycidae) of the islands of Andaman, India. Records of the Zoological Survey of India 45: 1-100.

Khan, T.N. \& T. Khan (1987). Biology of Nyphasia apicalis Gahan (Coleoptera: Cerambycidae) with particular emphasis on emergence and imaginal life, Proceedings of the Indian Academy of Science (Animal Sciences) 96(4): 403-415

Mukhopadhyay, P. \& S. Biswas (2000). Coleoptera: Cerambycidae,, pp. 41-67. In: Director (ed.). Fauna of Meghalaya, State Fauna Series 4 (Part 5). Zoological Survey of India, Kolkata, India.

Mukhopadhyay, P. \& S. Biswas (2002). Coleoptera: Cerambycidae, 139-142. In: Director (ed.). Fauna of Tripura, State Fauna Series 7 (Part 3). Zoological Survey of India, Kolkata, India.

Mukhopadhyay, P. \& S.K. Halder (2003). Insecta: Coleoptera: Cerambycidae, 181-199. In: Director (ed.). Fauna of Sikkim, State Fauna Series 9 (Part 3). Zoological Survey of India, Kolkata, India.

Mukhopadhyay, P. \& S.K. Halder (2004). Insecta: Coleoptera: Cerambycidae, 421-431. In: Director (ed.). Fauna of Manipur, State Fauna Series 10 (Part 2). Zoological Survey of India, Kolkata, India.

Raychaudhuri, D. \& S. Saha (2000). Longicorn beetles (Cerambycidae, Prioninae: Cerambycidae) of Buxa Tiger Reserve, Jalpaiguri, West Bengal. Journal of the Bombay Natural History Society 97(1): 74-91.

Rodgers, W.A., H.S. Panwar \& V.B. Mathur (2002). Wildlife Protected Area Network in India: A review (Executive Summary). Wildlife Institute of India, Dehra Dun, India.

Sama, G. (1991). Note sulla nomenclatura dei Cerambycidae della regione mediterranea (Coleoptera). Bollettino della Società Entomologica Italiana 123(2): 121-128.

Sen, A. \& H.V. Ghate (2006). Short notes on three species of Stibara (Cerambycidae: Lamiinae: Saperdini). Zoos' Print Journal 21(3): 2198; http://dx.doi.org/10.11609/JoTT.ZPJ.1420.2198

Sengupta, C.K. \& T. Sengupta (1981). Cerambycidae (Coleoptera) of Arunachal Pradesh. Records of the Zoological Survey of India 78: 133-154.

White, A. (1853). Catalogue of Coleopterus Insects in the Collection of British Museum. Longicornia I. Taylor and Francis, London. vii+174pp.

(http://www.cerambycoidea.com) accessed on $3^{\text {rd }}$ May 2013

(http://www.lamiinae.org) accessed on $3^{\text {rd }}$ May 2013 